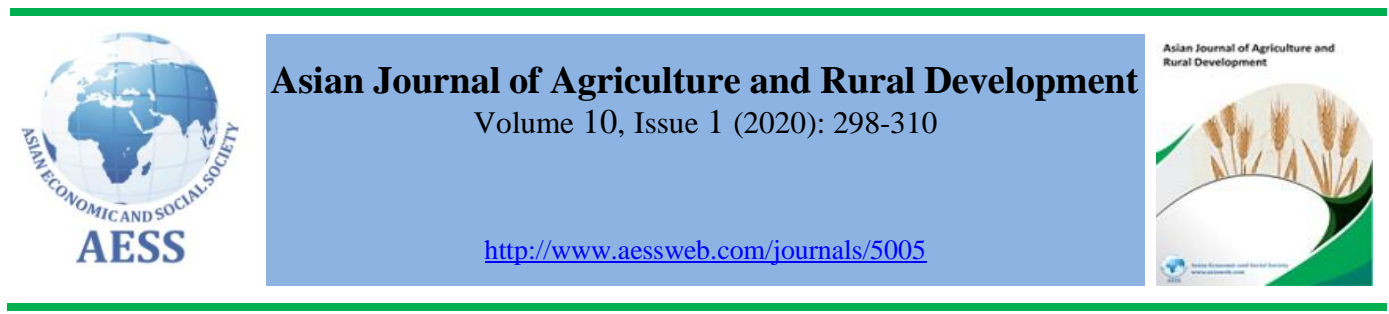

\title{
THE CAUSAL IMPACT OF GOVERNMENT SUPPORT ON THE SMALL STRATEGIC CROP INDUSTRY: MALAYSIA'S EXPERIENCE
}

\author{
Kamarudin Othman, Faculty of Business, Universiti Teknologi MARA, \\ Hapiza Omar, \\ Kedah, Malaysia \\ Hanani Ahmad Fuad , \\ Jamilah Laidin, \\ \ hanan5560@uitm.edu.my $($ Corresponding author) \\ Irlisuhayu Mohd Ramli
}

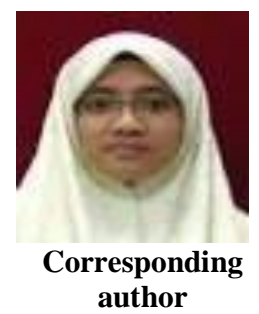

ARTICLE HISTORY:

Received: 24-Jan-2020

Accepted: 27-Apr-2020

Online Available: 26-May2020

\section{Keywords:}

ARDL,

Fertiliser subsidy,

Minimum price guarantee,

Paddy production,

Rice

ABSTRACT
Rice is a staple food for countries particularly in Asia, including Malaysia,
hence arise concern on its supply. Thus, this study aims to investigate the
causal relationship between the incentives (fertiliser subsidy and minimum
price guarantee) given and paddy production in Kedah, the rice bowl of
Malaysia. A time-series data ranging from the 1996 main season to the main
season in 2018 (1996H1 to 2018H1) employed. Using ARDL and Granger
approaches, the result shows that any disequilibrium in paddy production is
regulated to accomplish the convergence faster. In the short-run, fertiliser
subsidy and paddy prices are not significant in the MADA regions. The
results of the analysis show that there are various causes of the long-run in
the production of rice with subsidized steel and rice prices related to rice
yield. The outcome of this study demonstrates the presence of long-run
causality between paddy production with fertiliser subsidy and paddy price
with respect to paddy yield. Therefore, to boost the paddy yield, the
government should increase the number of subsidies, and control the paddy
price to prevent it from falling below the market price. Therefore, future
research should investigate the causal relationship between fertiliser and
paddy price subsidy to the different types of paddy seeds planted.

\section{Contribution/ Originality}

This study significantly contributes to the growing evidence of the relationship between government incentive schemes to paddy production in Malaysia. The research explored how fertiliser subsidy and minimum price guarantee contributed to paddy yield. The evidence provided in this study demonstrates that the presence of long-run causality between paddy production of fertiliser subsidy minimum price guarantee.

DOI: 10.18488/journal.1005/2020.10.1/1005.1.298.310

ISSN (P): 2304-1455/ISSN (E):2224-4433

How to cite: Kamarudin Othman, Hapiza Omar, Hanani Ahmad Fuad, Jamilah Laidin, and Irlisuhayu Mohd Ramli (2020). The causal impact of government support on the small strategic crop industry: malaysia's experience. Asian Journal of Agriculture and Rural Development, 10(1), 298-310.

(C) 2020 Asian Economic and Social Society. All rights reserved. 


\section{INTRODUCTION}

Paddy that is undoubtedly the principal crop in Malaysia represents the predominant source of the single Malaysians' staple food that is rice. Paddy planting areas cover almost $6 \%$ to $10 \%$ of the total agricultural areas in Malaysia (Economic Planning Unit, 2001, and 2006, Fatimah et al., 2020). Although rice is a staple food for Malaysians, by 2015 , more than $70 \%$ of the agricultural land was occupied by oil palm (Fatimah et al., 2020).

Paddy cultivation is initiated on a small scale and the average field size is 1 to 2 hectares. There are two types of paddy crops, namely wetland paddy, and dryland paddy. The average production for the main and off seasons is around 3000 kilograms per hectare. Based on these facts, it seems that the Malaysian paddy yield is below the national paddy production target at a rate of 5\% in 2010 (Food and Agriculture Organization, 2002; Othman, 2008; Department of Agriculture, Malaysia, 2011). The actual yield for rice production is between $44 \%$ to $68 \%$ and under the potential yield (Othman, 2008, Che et al., 2019). This situation causes a shortage of paddy production around $125,552.15$ metric tons per annum. The shortage of local paddy production also causes lower local rice supply. On average, rice consumption in Malaysia is roughly 120 kilograms per person every year. This is approximately $26 \%$ to $44 \%$ of the daily calorie needs (Suthida et al., 2008: USDA, 2012, Che et al., 2019). To solve these problems, the government has to import almost $30 \%$ of the rice from neighbouring countries such as Vietnam and Thailand. Therefore, to increase the rice self-sufficiency level (SSL), Malaysia has to increase its local paddy production. The tenth Malaysia plan aims to achieve a minimum self-sufficiency level of 70 percent food security (Saiful and Mohd, 2016). Thus, as to increase paddy production, farmers have to increase their level of productivity.

To increase Malaysian paddy production, the government has adopted various series of subsidy policies. The purpose of subsidy policies is basically to reduce the costs of production and to boost farmers' income. There are also subsidies given to reduce consumers' burden. Fundamentally, there are three instruments implemented under the subsidy policy, which are the fertiliser scheme, paddy price subsidy scheme, and rice price subsidy scheme. The fertiliser subsidy was introduced in the early 1950s. In the early stage, the government stopped the fertiliser subsidy when the price of fertilisers decreased. Nonetheless, in 1979, the government had to resume this policy when the price of fertilisers increased and until to date, fertilisers have become $100 \%$ subsidy. It was only given to the landowners and not to the operators. The average allocation of fertilisers for the years (20032007) was approximately USD 44.4 million. Meanwhile, the government introduced the paddy price subsidy scheme in 1980. The purpose of introducing this scheme was to increase the farmers' productivity and income (Tan, 1987; Tawang et al., 1999, Fatimah, 2018). The scheme was stemmed from the realisation that the paddy farmers have recorded the highest poverty rates in Malaysia. On average, the paddy price subsidy has increased over the years except in 2006 . However, the allocation gap between 2005 and 2006 had a minor difference of about $0.6 \%$. This proves that the paddy price subsidy is the major instrument in boosting the farmers' income. Therefore, the purpose of this study is to analyse the fertiliser and paddy price subsidy schemes on paddy cultivation based on the estimated paddy production function.

\section{LITERATURE REVIEW}

Among the most important inputs in agricultural production is fertiliser. The correct measurement of the fertiliser application may help to increase production output. Generally, fertilisers are classified into two, namely organic fertilisers and chemical fertilisers. Fertilisers are additional nutrients supplied to the plant. They are very important, especially in increasing the level of productivity among paddy farmers. The right application of the fertilisers and the right fertiliser specification help increase the nutrients in the soil, such as nitrogen, phosphorus, potassium, and others. The effective use of fertilisers may increase the output by more than $20 \%$. Therefore, fertilisers are crucial in 
increasing the fertility of the soil especially in unfertile paddy growing areas (Nurul et al., 2012; Meena et al., 2013).

Many of the researchers concluded that fertiliser inputs are complementary to the production of other inputs (Lori et al., 2013; Lenis et al., 2013; Adnan et al., 2017). In other words, to increase the paddy production, farmers have to make sure that they use effective technology and the correct schedule of fertilisers.

In a preliminary study of paddy, Jayaraman (1983) found that fertiliser is an important input in the paddy production in Indonesia. Meanwhile, in 2010, Krishna et al. (2010) discovered that fertiliser is an extremely important factor for the family farms in Nepal. Chaudhry et al. (2009) and Oluwatosin (2013) also discovered that fertiliser is significant in agricultural production.

In the efficiency study conducted by Sherlund et al. (2002), it was discovered that labour can be substituted by the use of chemical fertilisers. Furthermore, Suresh and Ready (2006) found that the ratio of MPV / MFC land in the district of Kerala, India is high, which is approximately 3:04. This means that land is significant as a determinant factor in paddy production. However, the size of the cultivated areas is small. This causes a low average output. Therefore, to increase paddy production, Ready (2007) suggested that the farmers in Kerala employ fertilisers. Furthermore, the results of the study indicated that one rupee increase in the fertiliser expenditure increases the yield by about 2.83 rupees in the Kerala district of India. The literature above shows strong evidence in supporting that fertilisers are very important in increasing the paddy yield.

Similar to other sectors, the agricultural output price also affects the allocation of resources to aggregate production (Liyan and Richard, 1993). Mundlak (1988), in his article, stressed the importance of price as an input to determine the choice of technique used. Furthermore, the price also important in influencing the level of productivity (Mundlak, 1988). When the price of agricultural output is high, farmers are given the incentive to improve their earning and, indirectly, it can help to raise the supply of the agricultural product. Numerous research has shown that price and productivity are positively related. Several studies have shown that price and productivity are positively related to the research in South Asia (Bhavani et al., 2019)

According to Timmer et al. (1983), two major roles played by price are, firstly, it shows the level of consumption especially among the poor. Secondly, the price also affects the supply through increased production as an incentive to producers. In reality, there are two different desires among consumers and agricultural producers. Consumers prefer lower prices of goods while farmers want a higher price of output. In the case of Malaysia, this difference is offset by the government through price subsidies for both consumers and agricultural producers.

\section{MATERIALS AND METHODS}

\subsection{Co-integration test: the ARDL approach}

The underlying regression for this section is based on the log-linear production model as follows:

$$
Y=(N, K, L 40, L 41, F, P)
$$

where $\mathrm{Y}$ is the paddy yield. Meanwhile, $\mathrm{F}$ and $\mathrm{P}$ represent fertiliser and paddy price subsidy schemes respectively. In the meantime, N, K, LL40, and LL41 are selected control variables for land, capital, young farmers, and old farmers. A natural $\log$ of both sides of equation 1 is taken and equation 2 will be obtained as follows:

$$
\ln Y_{t}=\alpha_{0}+\alpha_{1} \ln \left(N_{t}\right)+\alpha_{2} \ln \left(K_{t}\right)+\alpha_{3} \ln (L 40)+\alpha_{4} \ln (L 41)+\alpha_{5} \ln \left(F_{t}\right)+\alpha_{6} \ln \left(P_{t}\right)+\mu_{t}
$$


where $\alpha$ represents the elasticity of paddy production with respect to each independent variable in VAR model. Subscript $t$ represents time and $\mu$ represents the residual. Equation 2 is the underlying VAR that is used in the empirical analysis of all paddy production regions in MADA. The notation of $\alpha_{0}$ is the intercept, $\mu_{t}$ is white-noise random error, and $\alpha_{1}$ to $\alpha_{6}$ are the coefficients for the long-run model.

The F-statistic of the bounds testing method (Pesaran and Pesaran, 1997; Pesaran et al., 2001) is examined for the joint significance of the coefficients of the lagged levels of the variables. Every year has two main seasons. So all together 32 observations. This study employed the Narayan (2004) approach because critical values produced by Narayan is more suitable for small sample sizes. This study employs time-series data from the main season in 1996 (1996H1) to the main season in 2011 (2011H1). This study only focuses on the Muda Agricultural Development Authority (MADA) granary area.

The long-run equations which form the production functions model to be analysed in the present study can be portrayed as a general vector autoregressive model of order $p$ in $z_{t}$ as follows:

$$
z_{t}=a_{0}+\beta t+\sum_{i=1}^{p-1} \phi_{i} z_{t-i}+\varepsilon_{t}, t=1,2,3, \ldots, T
$$

where $a_{0}$ represents a $(\mathrm{k}+1)$ vector containing intercepts and $\beta$ is a $(\mathrm{k}+1)$ vector of trend coefficients. Following this, a vector equilibrium error-correction model (VECM) is derived as shown below:

$$
\Delta z_{t}=a_{0}+\beta t+\Pi z_{t-1}+\sum_{i=1}^{p-1} \Gamma_{i} \Delta z_{t-i}+\varepsilon_{t} \quad t=1,2,3, \ldots, T
$$

where the $(\mathrm{k}+1) \mathrm{x}(\mathrm{k}+1)$ matrices $\Pi=I_{k+1}+\sum_{i=1}^{p} \Psi_{i}$ and $\Gamma_{i}=-\sum_{j=i+1}^{p} \Psi_{j}$ with $i=1,2, \ldots, p-1$ have both the long-run multipliers and short-run dynamic coefficients of the VECM. $z_{t}$ contains the vector of variables $y_{t}$ and $x_{t}, y_{t}$ is the dependent variable and $x_{t}$ reflects the 'forcing' I (0) and I (1) variables. Assuming there is a unique long-run association between the parameters of interest, the VECM above can be written as:

$$
\Delta y_{t}=a_{y 0}+\beta t+\delta_{y y} y_{t-1}+\delta_{x x} x_{t-1}+\sum_{i=1}^{p-1} \lambda_{i} \Delta y_{t-i}+\sum_{i=0}^{p-1} \xi_{i} \Delta x_{t-1}+\varepsilon_{y t} t=1,2, \ldots, T
$$

In equation (5) above, $i$ refers to the paddy sub-sector, $\delta$ is the long-run multiplier, $a$ is constant, and $\varepsilon$ is the white-noise error.

Adapting the above specification to the variables in the present study, yield equations (6) and (7) below are for the production function model of paddy sub-sector:

$$
\begin{aligned}
& \Delta \ln Y_{t}=c_{0}+\delta_{1} \ln Y_{t-1}+\delta_{2} \ln N_{t-1}+\delta_{3} \ln K_{t-1}+\delta_{4} \ln L 40_{t-1}+\delta_{5} \ln L 41_{t-1}+\delta_{6} \ln F_{t-1}+ \\
& \delta_{7} \ln P_{t-1}+\sum_{j=0}^{q 1} \omega_{j} \Delta \ln N_{t-j}+\sum_{k=0}^{q 2} \gamma_{k} \Delta \ln K_{t-k}+\sum_{l=0}^{q 3} \emptyset_{l} \Delta \ln L 40_{t-l}+\sum_{m=0}^{q 4} \vartheta_{m} \Delta \ln L 41_{t-m}+ \\
& \sum_{n=0}^{q 5} \mu_{n} \Delta \ln F_{t-n}+\sum_{o=0}^{q 6} \tau_{o} \Delta \ln P_{t-o}+\varepsilon_{t}
\end{aligned}
$$




$$
\begin{aligned}
& \Delta \ln N_{t}=c_{0}+\delta_{1} \ln N_{t-1}+\delta_{2} \ln Y_{t-1}+\delta_{3} \ln K_{t-1}+\delta_{4} \ln L 40_{t-1}+\delta_{5} \ln L 41_{t-1}+\delta_{6} \ln F_{t-1}+ \\
& \delta_{7} \ln P_{t-1}+\sum_{j=0}^{q 1} \omega_{j} \Delta \ln N_{t-j}+\sum_{k=0}^{q 2} \gamma_{k} \Delta \ln K_{t-k}+\sum_{l=0}^{q 3} \emptyset_{l} \Delta \ln L 40_{t-l}+\sum_{m=0}^{q 4} \vartheta_{m} \Delta \ln L 41_{t-m}+ \\
& \sum_{n=0}^{q 5} \mu_{n} \Delta \ln F_{t-n}+\sum_{o=0}^{q 6} \tau_{o} \Delta \ln P_{t-o}+\varepsilon_{t} \\
& \ldots \ldots \ldots \ldots \ldots \ldots \ldots \ldots \ldots \ldots \ldots \ldots \ldots \ldots \ldots \ldots \ldots \ldots \ldots
\end{aligned}
$$

The OLS technique is used to conduct the F-test for the above equation which tests the null hypothesis $H_{0}: \delta_{1}=\delta_{2}=\delta_{3}=\delta_{4}=\delta_{5}=0 \quad$ against the alternate hypothesis $H_{1}: \delta_{1} \neq \delta_{2} \neq \delta_{3} \neq \delta_{4} \neq \delta_{5} \neq 0$. The rejection of the null hypothesis shows that there exists a long-run relationship between the variables. Therefore, the variables in the model are co-integrated. The F-statistic obtained is a statistic in a generalised Dickey-Fuller type of regression that employed to test the significance of lagged level variables in a conditionally unrestricted equilibrium-correction model (Pesaran et al., 2001). F-statistic is then compared with the two sets of critical values that create a band. The first value presumes all the variables are I (1) while another value presumes all the variables are I (0). Critical values for I (1) series are known as upper bound while the critical values for the I (0) series are known as lower bound.

If the computed F-statistic is beyond the upper-bound level, the null hypothesis can be rejected. This shows that there is a co-integration between the parameters or variables. However, if the F-statistic is below the lower-bound value, the null hypothesis cannot be rejected and this demonstrates no cointegration between variables. If the statistic falls between the upper and lower bounds, a conclusive inference cannot be made without knowing the order of integration of the independent variables (Narayan, 2004). If the variables are integrated I (1), then the upper bound is taken as the critical value. If the variables are integrated I (0), the lower bound becomes the critical value. In the meantime, there is also an alternative way to capture the existence of co-integration for the inclusive case. As mentioned by Kremers et al. (1992), the alternative way to capture the co-integration is by using the error-correction term (ECT). Additionally, the ECT value must be negative and significant. This condition indicates that there is a presence of adjustment towards the long-run equilibrium, therefore, the series are co-integrated.

The bounds table by Pesaran and Pesaran (1997) and Pesaran et al. (2001) has produced a sample size of 500 and 1,000 observations and 20,000 and 40,000 replications consecutively. However, the present study just employs 31 observations. Therefore, the F-statistic obtained compared by the critical values generated by Narayan (2004), which is more suitable for small sample sizes ${ }^{1}$. After establishing the presence of co-integration, the long-run relationship between the variables is estimated via the following conditional ARDL ( $\mathrm{p}, \mathrm{q}_{1}, \mathrm{q}_{2}, \mathrm{q}_{3}, \mathrm{q}_{4}, \mathrm{q}_{5}$ ), a long- run model for paddy subsector production function in equations (8) and (9) below:

$$
\begin{aligned}
& \Delta \ln Y_{t}=c_{0}+\sum_{i=1}^{p} \delta_{1} \Delta \ln N_{t-i}+\sum_{i=0}^{q 1} \delta_{2} \Delta \ln K_{t-i}+\sum_{i=0}^{q 2} \delta_{3} \Delta \ln L 40_{t-i}+\sum_{i=0}^{q 3} \delta_{4} \Delta \ln L 41_{t-i}+ \\
& \sum_{i=0}^{q 4} \delta_{5} \Delta \ln F_{t-i}+\sum_{i=0}^{q 5} \delta_{6} \Delta \ln P_{t-i}+\varepsilon_{t} \\
& \Delta \ln N_{i, t}=c_{i, 0}+\sum_{j=1}^{p} \delta_{1} \Delta \ln N_{i, t-j}+\sum_{l=0}^{q 1} \delta_{2} \Delta \ln K_{i, t-l}+\sum_{m=0}^{q 2} \delta_{3} \Delta \ln L 40_{i, t-m}+ \\
& \sum_{n=0}^{q 3} \delta_{4} \Delta \ln L 41_{i, t-n}+\sum_{o=0}^{q 4} \delta_{5} \Delta \ln F_{i, t-o}+\sum_{p=0}^{q 5} \delta_{6} \Delta \ln P_{i, t-p}+\varepsilon_{t}
\end{aligned}
$$

The optimal lag for each variable ( $\left.\mathrm{p}, \mathrm{q}_{1}, \mathrm{q}_{2}, \mathrm{q}_{3}, \mathrm{q}_{4}, \mathrm{q}_{5}\right)$ is selected based on Schwarz Bayesian Criterion (SBC) or Akaike Information Criterion (AIC).

After obtaining the long-run coefficient estimates, the short-run dynamic coefficients are estimated by OLS through the error-correction models associated with the long-run estimates. The error-

\footnotetext{
1 Narayan (2004) generated a different set of critical values using the same GAUSS code as Pesaran et al. (2001) but tailored his study with 31 observations. These new critical values were calculated using stochastic simulations for $\mathrm{T}=31$ and 40000 replications for the F-statistic.
} 
correction models corresponding to paddy sub-sector production functions are presented in equations (10) and (11) below:

$$
\begin{aligned}
& \Delta \ln Y_{i, t}=\beta_{i}+\sum_{j=1}^{p} \phi_{1} \Delta \ln N_{i, t-j}+\sum_{l=0}^{q 1} \varpi_{2} \Delta \ln K_{i, t-l}+\sum_{m=0}^{q 2} \varphi_{3} \Delta \ln L 40_{i, t-m}+ \\
& \sum_{n=0}^{q 3} \gamma_{4} \Delta \ln L 41_{i, t-n}+\sum_{o=0}^{q 4} \eta_{5} \Delta \ln F_{i, t-o}+\sum_{p=0}^{q 5} \eta_{6} \Delta \ln P_{i, t-p}+\vartheta e c t_{i, t-1}+\varepsilon_{i, t} \\
& \Delta \ln N_{i, t}=\beta_{i}+\sum_{j=1}^{p} \phi_{1} \Delta \ln N_{i, t-j}+\sum_{l=0}^{q 1} \varpi_{2} \Delta \ln K_{i, t-l}+\sum_{m=0}^{q 2} \varphi_{3} \Delta \ln L 40_{i, t-m}+ \\
& \sum_{n=0}^{q 3} \gamma_{4} \Delta \ln L 41_{i, t-n}+\sum_{o=0}^{q 4} \eta_{5} \Delta \ln F_{i, t-o}+\sum_{p=0}^{q 5} \eta_{6} \Delta \ln P_{i, t-p}+\vartheta e c t_{i, t-1}+\varepsilon_{i, t}
\end{aligned}
$$

In equations (10) and (11), the short-run coefficient estimates for the paddy sub-sector production function models are given by $\phi, \varpi, \varphi, \gamma, \eta, \varsigma$ each model converges to its long-run equilibrium. $\vartheta$ reflects how fast the equilibrium is achieved or how the speed of adjustment is.

\subsection{Granger causality}

If the co-integration test reveals that the variables are co-integrated, we employ the Vector ErrorCorrection (VEC) Model estimation as in equations 12 to 18y. The Error-Correction Model (ECM) is used to test for Granger-type causality. A benefit of using an ECM specification to test for causality is that it permits the testing of the short-run causality over the lagged different regressors. It also used to test the long-run causality over the lagged Error-Correction Term (ECT). A significant ECT confirms the presence of the long-run causality from the independent variables to the measured variable. Nevertheless, if the variables are not co-integrated, then Vector Autoregressive (VAR) Model is used in the first difference in the estimation given that both variables fertiliser and paddy price is I (1). Thus, ECM is used to examine the Granger causality between variables.

$$
\begin{aligned}
& \Delta L Y_{t}=\alpha_{0 Y}+\sum_{i-1}^{k} \delta_{1 Y} \Delta Y_{t-1}+\sum_{i-1}^{k} \delta_{2 Y} \Delta N_{t-1}+\sum_{i-1}^{k} \delta_{3 Y} \Delta K_{t-1}+\sum_{i-1}^{k} \delta_{4 Y} \Delta L L 40_{t-1} \quad+ \\
& \sum_{i-1}^{k} \delta_{5 Y} \Delta L L 41_{t-1}+\sum_{i-1}^{k} \delta_{6 Y} \Delta L F_{t-1}+\sum_{i-1}^{k} \delta_{7 Y} \Delta L P_{t-1}+\gamma_{1} E C T_{t-1}+\varepsilon_{t} \\
& \Delta L N_{t}=\alpha_{0 N}+\sum_{i-1}^{k} \delta_{1 N} \Delta N_{t-1}+\sum_{i-1}^{k} \delta_{2 N} \Delta Y_{t-1}+\sum_{i-1}^{k} \delta_{3 N} \Delta K_{t-1}+\sum_{i-1}^{k} \delta_{4 N} \Delta L L 40_{t-1}+ \\
& \sum_{i-1}^{k} \delta_{5 N} \Delta L L 41_{t-1}+\sum_{i-1}^{k} \delta_{6 N} \Delta L F_{t-1}+\sum_{i-1}^{k} \delta_{7 N} \Delta L P_{t-1}+\gamma_{2} E C T_{t-1}+\varepsilon_{t} \\
& \Delta L K_{t}=\alpha_{0 K}+\sum_{i-1}^{k} \delta_{1 K} \Delta K_{t-1}+\sum_{i-1}^{k} \delta_{2 K} \Delta K_{t-1}+\sum_{i-1}^{k} \delta_{3 K} Y N_{t-1}+\sum_{i-1}^{k} \delta_{4 K} \Delta L L 40_{t-1} \\
& \sum_{i-1}^{k} \delta_{5 K} \Delta L L 41_{t-1}+\sum_{i-1}^{k} \delta_{6 K} \Delta L F_{t-1}+\sum_{i-1}^{k} \delta_{7 K} \Delta L P_{t-1}+\gamma_{3} E C T_{t-1}+\varepsilon_{t} \\
& \Delta L L 40_{t}=\alpha_{0 L L 40}+\sum_{i-1}^{k} \delta_{1 L L 40} \Delta L L 40_{t-1}+\sum_{i-1}^{k} \delta_{2 L L 40} \Delta Y_{t-1}+\sum_{i-1}^{k} \delta_{3 L L 40} \Delta N_{t-1}+ \\
& \sum_{i-1}^{k} \delta_{4 L L 40} \Delta L K_{t-1}+\sum_{i-1}^{k} \delta_{5 L L 40} \Delta L L 41_{t-1}+\sum_{i-1}^{k} \delta_{6 L L 40} \Delta L F_{t-1}+\sum_{i-1}^{k} \delta_{7 L L 40} \Delta L P_{t-1}+ \\
& \gamma_{4} E C T_{t-1}+\varepsilon_{t} \\
& \Delta L L 41_{t}=\alpha_{0 L L 41}+\sum_{i-1}^{k} \delta_{1 L L 41} \Delta L L 41_{t-1}+\sum_{i-1}^{k} \delta_{2 L L 41} \Delta Y_{t-1}+\sum_{i-1}^{k} \delta_{3 L L 41} \Delta N_{t-1}+ \\
& \sum_{i-1}^{k} \delta_{4 L L 41} \Delta L K_{t-1}+\sum_{i-1}^{k} \delta_{5 L L 41} \Delta L L 40_{t-1}+\sum_{i-1}^{k} \delta_{6 L L 41} \Delta L F_{t-1}+\sum_{i-1}^{k} \delta_{7 L L 41} \Delta L P_{t-1}+ \\
& \gamma_{5} E C T_{t-1}+\varepsilon_{t} \\
& \Delta L F_{t}=\alpha_{0 L F}+\sum_{i-1}^{k} \delta_{1 L F} \Delta L F_{t-1}+\sum_{i-1}^{k} \delta_{2 L F} \Delta Y_{t-1}+\sum_{i-1}^{k} \delta_{3 L F} N Y_{t-1}+\sum_{i-1}^{k} \delta_{4 L F} \Delta L K_{t-1}+ \\
& \sum_{i-1}^{k} \delta_{5 L F} \Delta L L 41_{t-1}+\sum_{i-1}^{k} \delta_{6 L F} \Delta L L 41_{t-1}+\sum_{i-1}^{k} \delta_{7 L F} \Delta L P_{t-1}+\gamma_{6} E C T_{t-1}+\varepsilon_{t} \\
& \Delta L P_{t}=\alpha_{0 L P}+\sum_{i-1}^{k} \delta_{1 L P} \Delta L P_{t-1}+\sum_{i-1}^{k} \delta_{2 L P} \Delta Y_{t-1}+\sum_{i-1}^{k} \delta_{3 L P} \Delta N_{t-1}+\sum_{i-1}^{k} \delta_{4 L P} \Delta L K_{t-1}+ \\
& \sum_{i-1}^{k} \delta_{5 L P} \Delta L L 41_{t-1}+\sum_{i-1}^{k} \delta_{6 L P} \Delta L L 41_{t-1}+\sum_{i-1}^{k} \delta_{7 L P} \Delta L F_{t-1}+\gamma_{7} E C T_{t-1}+\varepsilon_{t}
\end{aligned}
$$

Where $E C T_{t-1}$ is the lagged error-correction term.

The Granger causality testing technique includes testing the significance of $\delta_{i j}$ s limited on the optimum lags. The ECM equations 12 to 18 are the alternative tests of causality. The $\gamma_{i j}$ is zero, 
which means that the variation in the dependent variable doesn't respond to the deviation in the longrun equilibrium in a period of $t-1$. For example, equation 1 , if $\gamma_{i j}$ is zero and all $\delta_{i j}$ is zero, that can be implied that all the variables do not Granger-cause paddy production. The insignificance of $t$ and F-statistic in the Wald test suggests that the variable is weakly exogenous.

If there is a presence of the co-integration between variables, we presume that at least one or all of the ECTs should be significantly non-zero. Granger causality between LY and other variables can be revealed by testing the following null hypothesis:

a) Short-run Granger causality:

$$
\begin{gathered}
\left(H_{O}: \delta_{2 Y}=0, \quad H_{O}: \delta_{2 N}=0, H_{O}: \delta_{2 K}=0, H_{O}: \delta_{2 L L 40}=0, H_{O}: \delta_{2 L L 41}=0, H_{O}: \delta_{2 L F}\right. \\
\left.=0 \text { and } H_{O}: \delta_{2 L P}=0,\right)
\end{gathered}
$$

b) Long-run Granger causality:

$$
\left(H_{O}: \gamma_{1}=0, H_{O}: \gamma_{2}=0, H_{O}: \gamma_{3}=0, H_{O}: \gamma_{4}=0, H_{O}: \gamma_{5}=0, H_{O}: \gamma_{6}=0 \text { and } H_{O}: \gamma_{7}=0\right)
$$

c) Joint Granger causality:

$$
\begin{aligned}
& \left(H_{O}=\delta_{2 Y}=\gamma_{1}=0, H_{O=} \delta_{2 N}=\gamma_{2}=0, H_{O=} \delta_{2 K}=\gamma_{3}=0, H_{O=} \delta_{2 L L 40}=\gamma_{4}=\right. \\
& \left.0, H_{O=} \delta_{2 L L 41}=\gamma_{5}=0, H_{O=} \delta_{2 L F}=\gamma_{6}=0 \text { and } H_{O=} \delta_{2 L P}=\gamma_{7}=0\right)
\end{aligned}
$$

\section{EMPIRICAL RESULTS}

Based on the results of the unit-root test, ARDL co-integration test, vector autoregressive (VAR) Granger-cause test in the framework of vector error-correction (VECM), response functions (IRFs), variance decomposition (VDS), and diagnostic tests shown in table 1 and 2. Table 1 displays the results of Augmented Dickey-Fuller (ADF) and Phillip Perron test (PP) to the paddy yield, land, capital, young farmers, old farmers, fertiliser, and paddy price to MADA paddy production areas. Based on these tests, at level, the absolute t-statistic obtained for all the time-series data fails to reject the null hypothesis of which the data are not stationary time series. This situation describes that, all

\begin{tabular}{|c|c|c|c|}
\hline Variables & $\begin{array}{c}\text { ADF Test } \\
\text { Constant Without Trend }\end{array}$ & $\begin{array}{c}\text { PP Test } \\
\text { Constant Without Trend }\end{array}$ & Conclusion \\
\hline LY & -1.696 & -2.041 & \multirow{2}{*}{$\mathrm{I}(1)$} \\
\hline$\Delta \mathrm{LY}$ & $-14.489 *$ & $-22.41 * *$ & \\
\hline $\mathrm{LN}$ & -1.037 & -1.455 & \multirow{2}{*}{$\mathrm{I}(1)$} \\
\hline$\Delta \mathrm{LN}$ & $-7.489 *$ & $-7.537 *$ & \\
\hline LK & 0.254 & 0.080 & \multirow{2}{*}{$\mathrm{I}(1)$} \\
\hline$\Delta \mathrm{LK}$ & $-4.465^{*}$ & $-4.465^{* *}$ & \\
\hline LL40 & -2.273 & -2.407 & \multirow{2}{*}{$\mathrm{I}(1)$} \\
\hline$\Delta \mathrm{LL} 40$ & $-6.125^{*}$ & $-6.108 *$ & \\
\hline LL41 & -2.083 & -2.198 & \multirow{2}{*}{$\mathrm{I}(1)$} \\
\hline$\Delta \mathrm{LL} 41$ & $-6.402 *$ & $-6.356^{*}$ & \\
\hline LF & -1.564 & -1.565 & \multirow{2}{*}{$\mathrm{I}(1)$} \\
\hline$\Delta \mathrm{LF}$ & $-6.779 *$ & $-6.611 *$ & \\
\hline LP & -0.115 & -0.051 & \multirow{2}{*}{$\mathrm{I}(1)$} \\
\hline$\Delta \mathrm{LP}$ & $-5.599 * *$ & $-5.599 * *$ & \\
\hline
\end{tabular}
factors not stationary at $1 \%$ and $5 \%$ significance level. This research proceeded with the firstdifference stationarity test and found out that the t-calculate was larger than the t-critical value at $1 \%$ and $5 \%$. This means that the integration of the variables is at the first difference or I(1).

Table 1: Unit-root analysis for MADA Regions

Notes: $*$, and ${ }^{* *}$ donated $1 \%$ and $5 \%$ significant levels respectively

To approve the existence of co-integration among the parameters, this study employed the bound test and the Autoregressive Distributed Lag (ARDL) method. The optimal lag length needs to be determined first before the ARDL co-integration test. Based on the AIC suggestion, the optimal lag 
length is 2. Table 2 shows that F-statistic for the MADA area is 3.4337. This F-statistic value is between the lower (2.303) and upper (3.483) bound value at 5\% and $10 \%$ significant levels. This indicates that the presence of co-integration between variables in the model could not be ascertained. Therefore, the test on the error correction term (ECT) by Kremers et al. (1992) is used to confirm the co-integration between variables. To test the ECT, the long-run equation for the MADA area needs to be generated first.

Table 2: Results of bounds test and critical values for case II

\begin{tabular}{lcc}
\hline Level of Significance & Case II (intercept and no trend) & Lower \\
\hline 1\% Significance & 3.901 & Upper \\
5\% Significance & 2.780 & 5.611 \\
10\% Significance & 2.303 & 4.084 \\
Computed F-statistic & & 3.483 \\
3.4337 & & \\
\hline
\end{tabular}

Notes: The F-statistics are compared with the upper bound i.e. I(1) and lower bound i.e. I(0) critical values for zero restriction on the coefficient of the lagged level variables

$\mathrm{N}=30$

Based on Table 3, the coefficient estimation shows that land, old farmers, fertilisers, and paddy prices are significant in the long-run equation for MADA. The coefficient estimation of land, fertilisers, and paddy price show that paddy yield is elastic towards change in land, fertilisers, and paddy price. $1 \%$ increase in land size leads to an increase in output by $28 \%$. Meanwhile, a $1 \%$ increase in fertilisers used triggers the increase in output by approximately $172 \%$. This reflects that the use of fertilizers intensively and effectively increases paddy yield. On the other hand, old farmers and paddy prices are inelastic to the change in paddy yield. If there is a $1 \%$ increase in the number of old farmers, the output decreases by about $0.4 \%$. Nonetheless, when the paddy price increases by $1 \%$, the output decreases by $5 \%$. Other variables are not significant to determine paddy yield in the long-run.

Table 3: Long-run coefficient estimations for the determinants of the paddy yield in MADA Area

\begin{tabular}{lccccccc}
\hline Variables & LN & LK & L40 & L41 & LF & LP & C \\
\hline Coefficient & $28.29^{* *}$ & -0.06 & 0.12 & $-0.04^{* *}$ & $172.35^{* *}$ & $-5.07^{* *}$ & $-1438.3 * *$ \\
t-statistic & 2.86 & -0.78 & 1.50 & -2.17 & 2.83 & -2.84 & -3.31 \\
\hline
\end{tabular}

Notes: $*, * *$ indicates significance at $5 \%$ and $10 \%$ levels

From the information in Table 3, we then computed the error-correction term (ECT). The negative and significant value of the error-correction term (ECT) shows the presence of the long-run relationship among variables. The Output Error-Correction Terms (ECT) for MADA are shown as below: -

$$
\begin{aligned}
& \Delta \mathrm{LY}=0.015+46.966 \Delta \mathrm{LN}^{* *}+0.449 \Delta \mathrm{LK}^{* *}+256.334 \Delta \mathrm{LL} 40^{*}-345.454 \Delta \mathrm{LL} 41^{* *} \\
& [1.445] \quad[4.083] \quad[2.986)] \quad[6.522)] \quad[-4.233] \\
& +93.228 \Delta \mathrm{LF}-2.851 \Delta \mathrm{LP}-1.038 \mathrm{ect}^{*} \\
& \text { [1.297] [-1.288] [-8.355] }
\end{aligned}
$$

$\mathrm{R}^{2}$ : 0.843; Adjusted R-squared: 0.793; AR(2): 0.970(0.396);

Heteroscedasticity (1): 0.891(0.559); RESET(2): 1.645(0.217);

Normality(2): 1.269(0.530); CUSUM: Stable; CUSUM-SQ: Stable 
Notes: Brackets denote the t-statistics while p-values are in parentheses. Breusch-Godfrey, White, Ramsey RESET, and Jarque Bera tests are used to test for the presence of serial correlation, heteroscedasticity, model miss-specification, and residual non-normality in the model.

$*$ and ${ }^{* *}$ denote significant at $1 \%$ and $5 \%$ level respectively. SR is short-run

From the above ECT estimation, we found that the value of ECT is negative and significant. This shows that there exists a long-run relationship among variables. The lagged coefficient of the errorcorrection term (ECT) depicts the speed of adjustment of paddy yield to shock in the system. The speed of adjustment of paddy production is higher. From the short-run output, the speed of adjustment for MADA is $104 \%$. The result suggested that any disequilibrium in paddy production is adjusted to achieve faster convergence. Additionally, it could be inferred from these results that paddy yield, land, capital, young and old farmers, fertilisers, and local paddy price are the long-run 'forcing variables' of paddy yield in MADA paddy production areas. From this result, we could make an initial assumption that at least there is a presence of one-way causality between variables in MADA paddy production areas.

The present study also found that in the short-run, the land is significant in the MADA areas. The degree of elasticity of paddy yield with respect to land is that it is elastic and has a positive sign. This means that $1 \%$ of the increase in paddy planting areas leads to approximately $46.97 \%$ of the increase in paddy yield. This indicates that in the short-run, the increase in harvested areas may increase the paddy yield (Fatimah et al., 2020). Besides, the present research also found that young and old farmers are also significant in influencing paddy production. The degree of elasticity of paddy yield concerning young and old farmers is elastic. However, both variables have a different sign. Young farmers have a positive effect on paddy yield; a $1 \%$ increase in young farmers, paddy yield increases roughly by $611 \%$. The increase in old farmers reduces paddy production by about $611 \%$. This indicates that young farmers are among the most vulnerable target to increases agricultural output (Balezentis et al., 2020). If paddy cultivation is too dependent on old farmers, the productivity may reduce. Nonetheless, this research also found that capital is significant in the short-run. From the above result, the degree of elasticity is inelastic and has a positive sign. Based on the empirical finding, a $1 \%$ increase in capital results in the increase of paddy yield by about $0.45 \%$. This finding is smaller as compared to the study done by Oniah et al. (2008).

The diagnostic test was then employed to test the goodness of fit of the model. The goodness of fit of the model is adequate as roughly $84 \%$ of the differences in paddy yield clarified by dissimilarities in the regressors. Additionally, there is no autocorrelation, no residual non-normality, and no missspecification problems associated with the MADA areas model. The present study also found that there is no heteroscedasticity in MADA. The CUSUM and CUSUM-Sq test in Figure 1 shows that the model parameters and residual variance are stable throughout the study.
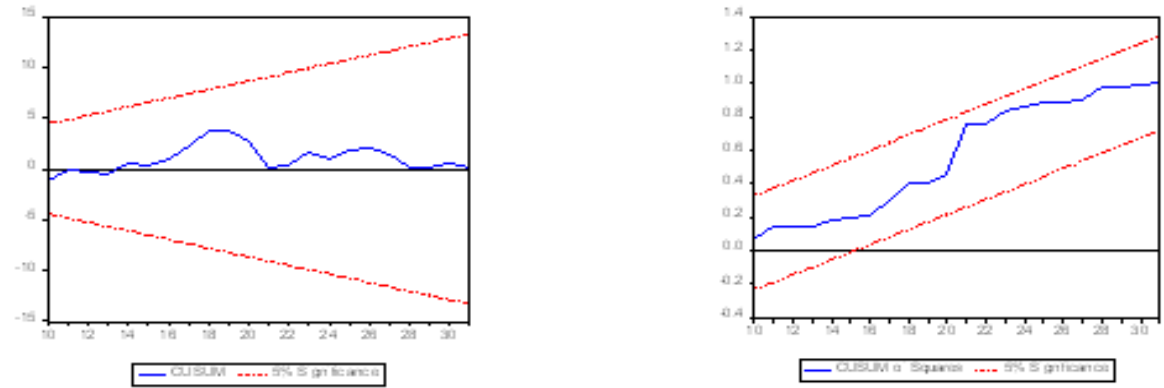

Figure 1: CUSUM and CUSUM-SQ Graphs for MADA paddy production

\subsection{Causal relationship}

The result from Table 4 shows that land and capital are significant at 5\% and $1 \%$ levels respectively in the paddy yield equation but there are no other explanatory variables that are significant in the 
short-run. Meanwhile, in the land and capital equation, paddy yield is significant at $5 \%$ and $1 \%$ levels. These clearly show that paddy yield and land, and paddy yield and capital both have a bidirectional Granger causality in the short-run. Furthermore, we also discovered that young farmers and capital, old farmers and capital, old farmers and young farmers, and paddy price and fertilisers also have the presence of bidirectional Granger causality.

Table 4: Short-run and long-run granger causality VEC Model

\begin{tabular}{|c|c|c|c|c|c|c|c|c|}
\hline $\begin{array}{l}\text { Variable } \\
\mathrm{s}\end{array}$ & $\Delta L Y_{t}$ & $\Delta L N_{t}$ & $\Delta L K_{t}$ & $\begin{array}{r}\Delta L L 40_{t} \\
\text { Wald } 1\end{array}$ & $\underset{\text {-statistics }}{\Delta L L 41_{t}}$ & $\Delta \boldsymbol{L F}_{\boldsymbol{t}}$ & $\Delta L P_{t}$ & $\begin{array}{c}\text { Long- } \\
\text { run } \\
\text { Causalit } \\
\mathbf{y} \\
\text { ECT }\end{array}$ \\
\hline$\Delta L Y_{t}$ & - & $\begin{array}{l}5.96 * * \\
{[0.02]}\end{array}$ & $\begin{array}{l}11.53^{*} \\
{[0.00]}\end{array}$ & $\begin{array}{c}0.89 \\
{[0.36]}\end{array}$ & $\begin{array}{c}0.20 \\
{[0.66]}\end{array}$ & $\begin{array}{c}1.38 \\
{[0.25]}\end{array}$ & $\begin{array}{c}1.39 \\
{[0.25]}\end{array}$ & $\begin{array}{c}1.03^{*} \\
(-7.85)\end{array}$ \\
\hline$\Delta L N_{t}$ & $\begin{array}{l}5.81 * * \\
{[0.03]}\end{array}$ & {$[0,-]$} & $\begin{array}{c}0.50 \\
{[0.49]}\end{array}$ & $\begin{array}{c}0.93 \\
{[0.35]}\end{array}$ & $\begin{array}{c}1.37 \\
{[0.26]}\end{array}$ & $\begin{array}{c}0.39 \\
{[0.54]}\end{array}$ & $\begin{array}{c}0.35 \\
{[0.56]}\end{array}$ & $\begin{array}{c}0.009 * * \\
(2.17)\end{array}$ \\
\hline$\Delta L K_{t}$ & $\begin{array}{c}24.99 * \\
{[0.00]}\end{array}$ & $\begin{array}{c}0.57 \\
{[0.46]}\end{array}$ & 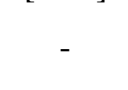 & $\begin{array}{l}11.30^{*} \\
{[0.00]}\end{array}$ & $\begin{array}{l}6.00 * * \\
{[0.02]}\end{array}$ & $\begin{array}{c}1.04 \\
{[0.32]}\end{array}$ & $\begin{array}{c}1.26 \\
{[0.27]}\end{array}$ & $\begin{array}{l}0.86^{*} \\
(4.10)\end{array}$ \\
\hline$\Delta L L 40_{t}$ & $\begin{array}{c}2.39 \\
{[0.14]}\end{array}$ & $\begin{array}{c}0.89 \\
{[0.36]}\end{array}$ & $\begin{array}{l}10.71 * \\
{[0.00]}\end{array}$ & 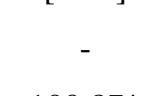 & $\begin{array}{c}101.66^{*} \\
{[0.00]}\end{array}$ & $\begin{array}{c}0.09 \\
{[0.77]}\end{array}$ & $\begin{array}{c}0.12 \\
{[0.73]}\end{array}$ & $\begin{array}{c}-0.0006 \\
(-1.58)\end{array}$ \\
\hline$\Delta L L 41_{t}$ & $\begin{array}{c}-.71 \\
{[0.41]}\end{array}$ & $\begin{array}{c}1.29 \\
{[0.27]}\end{array}$ & $\begin{array}{l}6.05^{* *} \\
{[0.02]}\end{array}$ & $\begin{array}{c}100.87 * \\
{[0.00]}\end{array}$ & - & $\begin{array}{c}2.68 \\
{[0.12]}\end{array}$ & $\begin{array}{c}2.48 \\
{[0.13]}\end{array}$ & $\begin{array}{c}0.0004 \\
(0.82)\end{array}$ \\
\hline$\Delta L F_{t}$ & $\begin{array}{c}2.13 \\
{[0.16]}\end{array}$ & $\begin{array}{c}0.38 \\
{[0.55]}\end{array}$ & $\begin{array}{c}0.82 \\
{[0.37]}\end{array}$ & $\begin{array}{c}0.09 \\
{[0.76]}\end{array}$ & $\begin{array}{c}2.63 \\
{[0.12]}\end{array}$ & 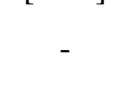 & $\begin{array}{l}5213^{*} \\
{[0.00]}\end{array}$ & $\begin{array}{l}0.001 \\
(1.53)\end{array}$ \\
\hline$\Delta L P_{t}$ & $\begin{array}{c}2.22 \\
{[0.15]}\end{array}$ & $\begin{array}{c}0.84 \\
{[0.37]}\end{array}$ & $\begin{array}{c}1.23 \\
{[0.28]}\end{array}$ & $\begin{array}{c}0.11 \\
{[0.74]}\end{array}$ & $\begin{array}{c}2.43 \\
{[0.13]} \\
\end{array}$ & $\begin{array}{c}50.80^{*} \\
{[0.00]} \\
\end{array}$ & 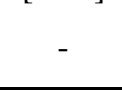 & $\begin{array}{r}-0.044 \\
(-1.43) \\
\end{array}$ \\
\hline
\end{tabular}

Notes: ( ) is t-statistic, [ ] is p value. *, **, and $* * *$ shows $1 \%, 5 \%$, and $10 \%$ level of significance respectively

Based on t-statistic, it could be seen that the coefficient of ECT is significant in the paddy yield, land, and capital equations. Meanwhile, ECT is found to be insignificant in fertilisers, young and old farmers, and paddy price equations. This implies that paddy yield, land, and capital carry out the short-run adjustment to the long-run equilibrium. Based on the paddy yield equation, the deviation of paddy yield from the long-run equilibrium, and all the seven variables interact ineffective way to restore the long-run equilibrium.

Joint Granger causality in Table 5 suggests that the presence of bidirectional causality in capital and land, young farmers and land, young farmers and capital, old farmers and capital, old farmers and young farmers, fertilisers and old farmers, fertilisers and young farmers, and paddy price and fertilisers have the presence of two-way short-run Granger causality. There are also a few variables having a one-way Granger causality such as young farmers Granger-cause paddy yield, old farmers Granger-cause paddy yield, fertilisers Granger-cause paddy yield, and paddy price Granger-cause paddy yield.

Table 5: Joint causality Granger causality VEC model 


\begin{tabular}{|c|c|c|c|c|c|c|c|}
\hline \multirow{4}{*}{ Variables } & \multicolumn{7}{|c|}{ MADA Joint Causality } \\
\hline & ECT & ECT & ECT & ECT & ECT & ECT & ECT \\
\hline & $\Delta L Y_{t}$ & $\Delta L N_{t}$ & $\Delta L K_{t}$ & $\Delta L L 40_{t}$ & $\Delta L L 41_{t}$ & $\Delta L F_{t}$ & $\Delta L P_{t}$ \\
\hline & \multicolumn{7}{|c|}{ Wald F-statistics } \\
\hline \multirow{2}{*}{$\Delta L Y_{t}$} & & $32.22 *$ & $30.83^{*}$ & $31.95^{*}$ & $31.74^{*}$ & $30.82 *$ & $30.83^{*}$ \\
\hline & - & {$[0.00]$} & {$[0.00]$} & {$[0.00]$} & {$[0.00]$} & {$[0.00]$} & {$[0.00]$} \\
\hline \multirow{2}{*}{$\Delta L N_{t}$} & $2.91 * * *$ & & $3.14 * * *$ & $4.98 * *$ & $4.30 * *$ & 2.36 & 2.36 \\
\hline & [0.08] & - & {$[0.07]$} & {$[0.02]$} & {$[0.03]$} & [0.12] & {$[0.12]$} \\
\hline \multirow{2}{*}{$\Delta L K_{t}$} & $12.49^{*}$ & $9.47 *$ & & $16.42 *$ & $14.09 *$ & $8.44 *$ & $8.49 *$ \\
\hline & {$[0.00]$} & {$[0.00]$} & - & {$[0.00]$} & {$[0.00]$} & {$[0.00]$} & [0.00] \\
\hline \multirow{2}{*}{$\Delta L L 40_{t}$} & 1.29 & $3.02 * * *$ & $5.49 * *$ & & $63.23 *$ & 1.27 & 1.26 \\
\hline & [0.29] & [0.07] & {$[0.01]$} & - & {$[0.00]$} & {$[0.30]$} & [0.31] \\
\hline \multirow{2}{*}{$\Delta L L 41_{t}$} & 0.36 & 1.64 & $3.58 * *$ & $57.34 *$ & & $2.75 * * *$ & $2.61 * *$ \\
\hline & [0.69] & {$[0.22]$} & {$[0.05]$} & {$[0.00]$} & - & {$[0.08]$} & [0.09] \\
\hline \multirow{2}{*}{$\Delta L F_{t}$} & 1.18 & 1.17 & 1.17 & 1.18 & $3.72 * *$ & & $2627 *$ \\
\hline & [0.33] & [0.33] & [0.33] & [0.33] & {$[0.04]$} & & [0.00] \\
\hline \multirow{2}{*}{$\Delta L P_{t}$} & 1.12 & 1.08 & 1.04 & 1.03 & $3.33 * * *$ & $2561 *$ & - \\
\hline & {$[0.35]$} & {$[0.36]$} & {$[0.37]$} & {$[0.38]$} & {$[0.06]$} & {$[0.00]$} & \\
\hline
\end{tabular}

Notes: ( ) is t-statistic, [ ] is p value. *, **, and *** shows $1 \%, 5 \%$, and $10 \%$ level of significance respectively

\section{CONCLUSION}

In the short-run, fertiliser subsidy and paddy prices are not significant in the MADA regions. This indicates that fertiliser subsidy and paddy prices do not give any significant effects to the local paddy production in the short run. Nonetheless, in the long-run, fertiliser subsidy and paddy prices have a positive relationship and are significant with respect to paddy yield. Although fertiliser subsidy and paddy prices are significant with paddy yield, the relationship between paddy price and paddy yield is negative. This means that when paddy price increases, paddy yield decreases. Poor soil fertility and the awful weather condition might be the cause of this negative relationship. The present research also discovered the presence of one-way short-run causality between fertilisers and paddy yield in the MADA regions. This clearly shows that any shock in fertilisers will increase paddy yield. Fertiliser is considered as one of the most important non-traditional inputs in paddy production. The evidence from the Granger causality analysis shows that fertilisers play an important role in causing the rise in paddy output in the MADA regions. Therefore, the government should provide information and knowledge related to the use of fertilisers to paddy farmers. The government should also reduce the price of fertilisers by increasing the number of subsidies. Also, paddy farmers themselves should have a better understanding of how to use the fertilisers efficiently. They should also follow the fertilising schedule provided by the government to raise the paddy yield. Therefore, researchers should expand the study further by investigating the causal relationship between fertiliser subsidy and paddy price subsidy to different types of paddy seeds planted.

Funding: This study did not receive any specific financial support.

Competing Interests: The authors declared that they have no conflict of interests.

Contributors/Acknowledgement: The authors would like to express their gratitude to everyone who involved directly or indirectly in completing this study. The causal impact of government support on the small strategic crop industry: Malaysia's experience.

Views and opinions expressed in this study are the views and opinions of the authors, Asian Journal of Agriculture and Rural Development shall not be responsible or answerable for any loss, damage or liability, etc. caused in relation to/arising out of the use of the content.

\section{References}


Adnan, N., Nordin, S. M., Rahman, I., \& Noor, A. (2017). The impacts and visions of the green fertilizer technologies (GFT). World Journal of Science, Technology and Sustainable Development, 14(4), 336-354. doi.org/10.1108/wjstsd-08-2016-0053.

Balezentis, T., Ribasauskiene, E., Morkunas, M., Volkov, A., Streimikiene, D., \& Toma, P. (2020). Land use policy young farmers' support under the common agricultural policy and sustainability of rural regions: evidence from Lithuania. Land Use Policy, 94(February), 104542. https://doi.org/10.1016/j.landusepol.2020.104542.

Bhavani, S., Nigel, P., \& Frances, A. B. (2019). Agricultural inputs and nutrition in South Asia. Food Policy, Elsevier, 82, 28-38. doi.org/10.1016/j.foodpol.2018.10.011.

Chaudhry, I. M., Khan, M. B., \& Anwar, M. (2009). Factors affecting cotton production in Pakistan: empirical evidence from Multan district. MPRA, 5(2), 91-100.

Che, O. S., Shaharudin, A., \& Tumin, S. A. (2019). The status of the paddy and rice industry in Malaysia. in Khazanah research institute. Malaysia http://www.krinstitute.org/assets/contentMS/img/template/editor/20190409_RiceReport_Ful 1Report_Final.pdf.

Department of Agriculture, Malaysia (2011). Pembangunan industri padi. Retrived on January 2, 2010 from http://www.doa.gov.my/c/document.../get file?

Economic Planning Unit (2001). Eight Malaysia plan (2001-2005). Kuala Lumpur, Prime Minister's Department.

Economic Planning Unit (2006). Ninth Malaysia plan (2006-2010). Kuala Lumpur, Prime Minister's Department.

Fatimah, K. (2018). Evaluation of agricultural subsidies and the welfare of farmers: Malaysia agricultural subsidies report 2018. in IDEAS Policy Research Berhad, Kuala Lumpur.

Fatimah, M. A., Kusairi, M. N., Bach, N. L., Illisriyani, I., Abdulla. I., Gregory, H. W. S., Siti, A. T., \& Ahmad, A. A. S. (2020). Implications of the dominant shift to industrial crops in Malaysian agriculture. phase i : system dynamics model of the paddy and rice sector, In Khazanah Research

Institute. http://www.krinstitute.org/assets/contentMS/img/template/editor/0.Full\%20report\%2020041 0. pdf.

Food and Agriculture Organization (2002). Selected indicators of food and agriculture development in the asia-pacific region 1992-2002. Food and Agriculture Organization of The United Nations, Regional Office for Asia and the Pacific. Bangkok. Retrieved on January 2, 2010 from ftp://ftp.fao.org/docrep/fao/004/AD452e/ad452e00.pdf.

Jayaraman, T. K. (1983). Determinants of paddy production in Indonesia: 1972-1981, A Simultaneous Equation Model Approach. Asian Development Bank, Economic Office, Manila

Kremers, J., Ericsson, N., \& Dolado, J. (1992). The power of cointegration tests. Oxford Bulletin of Economics and Statistics, 54, 349-367.

Krishna, M., Yasuhiro, A., \& Hideyuki (2010). Estimation of production function and resource use condition of organic coffee cultivation in different farm size and altitude categories in the hill region of Nepal. European Journal of Scientific Research, 45(3), 438-449.

Lenis, S., Liverpool, T., \& Sheu, S. (2013). Spillover effects of targeted subsidies an assessment of fertilizer and improved seed use in Nigeria. International Food Policy Research Institute (IFPRI) Discussion Paper 01260, Retrieved on Mac 4, 2013 from http://www.ifpri.org/sites/default/files/publications/ifpridp01260.pdf.

Liyan, E. F., \& Richard, K. P. (1993). Prices and productivity in agriculture. The Review of Economics and Statistics, 75(3), 471-482.

Lori, B., Dean, K., Bram, T., \& Christopher, U. (2013). Probability of fertilizer: experimental evidence from female rice farmers in mali. Economics Department Working Paper No. 111, Department of Economics, Yale University, Retrieved on Mac 4, from http://www.econ.yale.edu/growth_pdf/cdp1020.pdf. 
Meena, D. S., Meena, V. R., \& Meena, A. K. (2013). Fertilizer management studies on growth and productivity of hybrid Indian mustard Brassica juncea (L). Journal of Oilseed Brassica, 4(1), 39-42.

Mundlak, Y. (1988). Endogenous technology and measurement of productivity. In S.M. Capalbo and J.M. Antle (Ed.), Agricultural productivity: measurement and explanation, Washington D.C.

Narayan, P. K. (2004). Reformulating critical values for the bounds F-statistics approach to cointegration: An application to the tourism demand model for Fiji. Department of Economics Discussion Papers No. 02/04, Monash University, Australia.

Nurul, N. R., Mad, Nasir, S., Zainalabidin, M., \& Alias, R. (2012). The impact of fertilizer subsidy on Malaysia paddy/rice industry using a system dynamics approach. International Journal of Social Science and Humanity, 2(3), 213-219.

Oluwatosin, O. F. (2013). Determinants of perceived effectiveness of organic fertilizer used by farmers in Oyo State, Nigeria. Agricultura Tropica Et Subtropica, 46/1, 23-28.

Oniah, M. O., Kuye, O. O., \& Idiong, I. C. (2008). Efficiency of resource use in small scale seamp rice production in Obubra local government area of cross river state, Nigeria. Middle-East Journal of Scientific Research, 3(3), 145-148.

Othman, O. (2008). Rice production and potential for hybrid rice in Malaysia. In International Plantation Industry Conference and Expo - IPiCEX. Shah Alam. Malaysia.

Pesaran, M. H., \& Pesaran, B. (1997). Working with Microfit 4.0: interactive econometric analysis. Oxford University Press, Oxford.

Pesaran, M. H., Shin, Y., \& Smith, R. J. (2001). Bounds testing approaches to the analysis of level relationships. Journal of Applied Econometrics, 16, 289-326.

Ready, G. P. (2007). Impact of water management on production of rice in Balipatna command area or Orissa, India. Sabaragamnwa University Journal, 1(2), 15-20.

Saiful, N. S. B., \& Mohd, R. M. (2016), Distributional effects of non-farm incomes in a Malaysian rice bowl. International Journal of Social Economics, 43(2), 205-220.

Sherlund, S. M., Christopher, B. B., \& Akinwumi A. A. (2002). Smallholder technical controlling for environmental production conditions. Journal of Development Economics, 69, 85-101.

Suresh, A., \& Ready, T. R. K. (2006). Resource-use efficiency of paddy cultivation in Peechi command area of Thrissur district of Kerala: an economic analysis. Agricultural Economics Research Review, 19, 159-171.

Suthida, W., Gil, R., \& Jammie, P. (2008). Changing food consumption and import in Malaysia, opportunities for Australian agricultural export, Australia Bureau of Agricultural and Resources Economics, Research Report 08.6 August 2008.

Tan, S. H. (1987). Malaysia's rice policy: a critical analysis. Institute of Strategic and International Studies (ISIS), Malaysia 1987.

Tawang, A., Ariffin, T. M., \& Ahmad, T. (1999). Effects of trade liberalization on agriculture in Malaysia: commodity aspects. Working Paper No. 46, CGPRT Centre, Bogor, September 1999.

Timmer, C., Peter, W., Falcon, P., \& Scott, R. P. (1983). Food policy analysis. Baltimore, Md., The Johns Hopkins University Press.

USDA Foreign Agricultural Service (2012). Global agricultural information network report. Retrieved from http://static.globaltrade.net/files/pdf/20110406115103794.pdf. 